\title{
ACOMPANHANTE TERAPÊUTICO E A PRÁTICA DA TERAPIA COGNITIVO- COMPORTAMENTAL: encontros e desencontros
}

Rita de Cássia Neres Pinto ${ }^{1}$

Résia Silva de Morais ${ }^{2}$

\section{RESUMO}

INTRODUÇÃO: A prática desenvolvida pelo Acompanhante Terapêutico (AT) ainda é pouco difundida, pois são poucos os trabalhos voltados para esta modalidade de atuação, apesar da grande importância deste profissional no processo psicoterapêutico. Hipotetiza-se que a intervenção do Acompanhamento Terapêutico (AT) juntamente com a aplicabilidade de técnicas da Terapia Cognitivo-Comportamental (TCC) no ambiente natural do paciente proporcione uma melhora de seu quadro, como também uma melhor qualidade de controle de comportamentos desadaptativos, reestabelecendo 0 desempenho de atividades cotidianas. OBJETIVO: O presente estudo tem como objetivo desenvolver uma pesquisa buscando a relação da Terapia Cognitivo-Comportamental (TCC) e do Acompanhamento Terapêutico (AT) diante da prática, bem como fazer o diálogo entre os mesmos. MÉTODO: O estudo realizado refere-se a uma pesquisa bibliográfica, utilizando como fonte de pesquisa livros, dissertações e as bases de dados: Google Acadêmico, Scielo (Scientific Electronic Library Online), Pepsic (Periódicos Eletrônicos em Psicologia) e como estratégia de busca, foram utilizadas as seguintes palavras-chave: "Terapia Cognitivo-Comportamental", "Acompanhante Terapêutico". Não foram estabelecidos períodos específicos de publicação devido à escassez de estudos voltados para esta temática. RESULTADOS: Após a pesquisa inicial dos artigos, foram encontrados 43 resultados na base do Google Acadêmico, selecionando apenas 4 estudos. Na base Pepsic a pesquisa resultou em 3 artigos, sendo apenas 2 selecionados. Na base Scielo foram encontrados 5 resultados, porém somente 1 foi utilizado. Desta forma, os dados da pesquisa bibliográfica foram esquematizados em uma

\footnotetext{
${ }^{1}$ Acadêmica do curso de psicologia da Faculdade Patos de Minas - FPM. E-mail de contato: ritanerespsic@gmail.com

${ }^{2}$ Docente do departamento de psicologia da Faculdade Patos de Minas - FPM.
} 

tabela e resultaram em um total de 7 artigos. DISCUSSÃO: No decorrer dos anos a terapia cognitivo-comportamental vem exercendo atendimentos extra consultório. As intervenções em situação natural, exigem algumas qualificações para o estudante que se compromete ao serviço de acompanhante terapêutico em abordagem comportamental, entre elas se pode citar: habilidade em observação, possuir conhecimento de definições essenciais de análise do comportamento, entender procedimentos de entrevistas, capacidade de demonstrar vínculo terapêutico, dispor de entendimento na realização das técnicas e ter noções básicas de drogas psicoativas para o tratamento de transtornos mentais. O acompanhamento terapêutico surge como uma recente prática não somente para a análise do comportamento, mas para a psicologia de modo geral por se tratar de uma modalidade interventiva que complementa o tratamento medicamentoso e a terapia tradicional em consultório, demonstrando sua eficácia em diferentes casos. CONSIDERAÇÕES FINAIS: Conclui-se, então, que tanto o Acompanhamento Terapêutico quanto a Terapia CognitivoComportamental visam estimular o desenvolvimento de comportamentos mais adaptativos, resgatar potencialidades, propor a reinserção social do paciente e a busca pela sua autonomia. Entende-se que as características do AT são similares à prática clínica, visto que a compreensão do fenômeno humano parte do mesmo pressuposto filosófico do behaviorismo radical.

Palavras-chave: Acompanhante Terapêutico; Terapia cognitivo-comportamental; Técnicas; Extraconsultório. 